\title{
An Examination of Employment Model and Policy and Procedure Practices of Secondary School Athletic Trainers
}

\author{
Micaela Dunbar-Gaynor \\ Adrian College, mdunbar-gaynor@adrian.edu \\ Ericka P. Zimmerman \\ Western Carolina University, epzimmerman@wcu.edu \\ Victor Liberi \\ Adrian College, vliberi@adrian.edu
}

Follow this and additional works at: https://nsuworks.nova.edu/ijahsp

Part of the Sports Sciences Commons

\section{Recommended Citation \\ Dunbar-Gaynor M, Zimmerman EP, Liberi V. An Examination of Employment Model and Policy and Procedure Practices of Secondary School Athletic Trainers. The Internet Journal of Allied Health Sciences and Practice. 2021 Jan 01;19(1), Article 14.}

This Manuscript is brought to you for free and open access by the College of Health Care Sciences at NSUWorks. It has been accepted for inclusion in Internet Journal of Allied Health Sciences and Practice by an authorized editor of NSUWorks. For more information, please contact nsuworks@nova.edu. 


\title{
An Examination of Employment Model and Policy and Procedure Practices of Secondary School Athletic Trainers
}

\begin{abstract}
Purpose: The purpose of this study was to identify the policy and procedure practices of secondary school athletic trainers based on employment models. Methods: Following an online informed consent confirmation, participants completed a Policies and procedures status questionnaire, including demographics. This was distributed to certified athletic trainers currently employed in the secondary school setting in the United States. The survey consisted of 49 questions about the status of policies and procedures being in operation and/or written form. Results from the policies and procedures questionnaire were combined with the recorded employment model type to compare the status of policies and procedures between employment models. This study utilized descriptive and inferential statistics consisting of means, frequencies, percentages, and chi square analyses to report results that described and compared the current status of policies and procedures based on employment model. Results: There was a total of 232 participants. Fifty-nine percent (59.9\%) of participants were directly employed athletic trainers and $40.1 \%$ were outreach employed athletic trainers. Policy and procedure manuals were in existence according to $72 \%$ of the participants. A total of 49 variables were inquired about. Of the 26 clinically significant (pConclusion: The results revealed that athletic trainers who identified the outreach employment model were more likely to have policies in both operation and in written form over those identifying with the directly employed model.
\end{abstract}

\section{Author Bio(s)}

Micaela Dunbar-Gaynor, MS, ATC, EMC is currently a post-graduate student in Livonia, Michigan.

Ericka P. Zimmerman, EdD, LAT, ATC is the School Director and Associate Professor of the School of Health Sciences at Western Carolina University in Cullowhee, NC.

Victor Liberi, MS, LAT, ATC is an Associate Professor of Exercise Science and Athletic Training at Adrian College in Adrian, Michigan. 


\title{
IJAHSP \\ The Internet Joutnal of Allied Health Sciences and Practice
}

Dedicated to allied health professional practice and education

Vol. 19 No. 1 ISSN 1540-580X

\section{An Examination of Employment Model and Policy and Procedure Practices of Secondary School Athletic Trainers}

\author{
Micaela Dunbar-Gaynor ${ }^{1}$ \\ Ericka P. Zimmerman² \\ Victor Liberi' \\ 1. Adrian College \\ 2. Western Carolina University \\ United States
}

\begin{abstract}
Purpose: The purpose of this study was to identify the policy and procedure practices of secondary school athletic trainers based on employment models. Methods: Following an online informed consent confirmation, participants completed a Policies and procedures status questionnaire, including demographics. This was distributed to certified athletic trainers currently employed in the secondary school setting in the United States. The survey consisted of 49 questions about the status of policies and procedures being in operation and/or written form. Results from the policies and procedures questionnaire were combined with the recorded employment model type to compare the status of policies and procedures between employment models. This study utilized descriptive and inferential statistics consisting of means, frequencies, percentages, and chi square analyses to report results that described and compared the current status of policies and procedures based on employment model. Results: There was a total of 232 participants. Fifty-nine percent (59.9\%) of participants were directly employed athletic trainers and $40.1 \%$ were outreach employed athletic trainers. Policy and procedure manuals were in existence according to $72 \%$ of the participants. A total of 49 variables were inquired about. Of the 26 clinically significant $(p<.05)$ variables in the "operational" category, $75.5 \%$ of outreach employed athletic trainers reported having these risk management practices in operation, whereas $64.8 \%$ of directly employed athletic trainers reported having the same risk management practices in operation. Of the 40 clinically significant $(p<.05)$ variables in the "written" category, $62 \%$ of outreach employed athletic trainers reported having these risk management practices in written form whereas $41.8 \%$ of directly employed athletic trainers reported having the same risk management practices in written form. Conclusion: The results revealed that athletic trainers who identified the outreach employment model were more likely to have policies in both operation and in written form over those identifying with the directly employed model.
\end{abstract}

Key Words: policy and procedure, secondary schools, athletic trainers, risk management, employment model 


\section{INTRODUCTION}

The athletic trainer (AT) is a critical member of the athletic health care team and is responsible for implementing important risk management practices. ${ }^{1}$ To minimize risk of liability for athletic injuries and prevent sudden death, a comprehensive risk management plan is needed to increase the likelihood that policies, procedures, and current practice standards are upheld. ${ }^{2}$ Policies and procedures manuals assist in organizing the athletic training department's risk management policies for daily functions as well as preparation for emergency situations. These manuals provide clarity and consistency for the athletic health care team with daily operations or emergency situations. ${ }^{3}$ The BOCs "Guiding Principles for AT Policies and Procedure Development" states policies and procedures are a critical component of a risk management plan that provides clarity when dealing with issues and activities that are critical to health and safety, legal liabilities and regulatory requirements. ${ }^{3} \mathrm{~A}$ policy and procedure manual guides operations in the AT facility. This can include daily functions such as documentation. It can also include response to injuries and emergencies from sudden cardiac arrest to environmental dangers. The NATA has published a sample outline of policies and procedures titled "standard operating policies and procedures" as a guideline for what an athletic training department should include in the manual. ${ }^{4}$

ATs work in a variety of employment settings and employment models. The NATA reports that $19 \%$ of ATs are employed at colleges/universities, $18 \%$ at secondary schools, $17 \%$ at clinics and hospitals, $2 \%$ with professional sports and $2 \%$ in emerging settings. ${ }^{5}$ In 1994 , only $35 \%$ of secondary schools had AT services compared to a recent 2015 study where it was revealed that $70 \%$ of secondary schools now offered AT services. ${ }^{6}$ Of those secondary schools that responded to the 2015 survey, $37 \%$ offered full-time services, $31 \%$ offered part-time services, and only $2 \%$ offered per diem AT services. ${ }^{6}$ ATs can work full-time, defined as 40+ hours a week without additional stipends or part-time, defined as 20-30 hours a week performing strictly AT duties or even per diem, which is defined as an AT paid per day. ${ }^{7}$ ATs can also be directly employed by the secondary school that they work for or be considered outreach, which is an AT that is not directly employed by the secondary school but is hired through a company and then contracted out to the secondary school.

Studies have assessed policies and procedures in the secondary schools from a variety of perspectives. ${ }^{8-15}$ There is limited research on the employment model of athletic trainers. $9,14,16$ There is one study examining the awareness of academic accommodation services for concussed student in secondary schools which did compare direct and outreach employed ATs. ${ }^{13}$ However, research is lacking on the overall policy and procedure practices of secondary school athletic trainers by employment model -- direct employment and outreach employment.

\section{METHODS}

The policies and procedures questionnaire was distributed to 4000 ATs in the secondary school setting in the United States who were certified athletic trainers currently working in the secondary school setting. Participants were randomly selected from a pool of NATA members who were certified athletic trainers or certified athletic training students currently employed in the secondary school setting. The survey was conducted using a Google Form. A cover e-mail message described the purpose and importance of the study, with a link to the survey. Participants were asked to complete an informed consent form prior to completing the questionnaire. Participants completed the survey by clicking on the appropriate boxes. Two e-mail reminders were sent at twoweek intervals. The Institutional Review Board at Adrian College approved this study.

\section{Survey Instrument}

This was a descriptive study using two types of questions to describe policy and procedure status. The policies and procedures status questionnaire was created by the current researcher with inspiration from Zimmerman's study on collegiate schools; this instrument had an acceptable reliability $(\alpha=.70) .{ }^{17}$ The survey consisted of 49 questions about the status of specific policies and procedures using one of the following responses: the practice is in operation and it appears in written form; the practice is in operation but does not appear in written form; the practice is not in operation but does appear in written form; and the practice is not in operation and it does not appear in written form. Demographic questions were asked, including questions about age, sex, state, employment setting, years employed total, years employed at current setting, employment model, work hours per week, level of education, educational path, resource use, and policy and procedure manual existence. The response for employment model was used to compare the status of policies and procedures between employment models.

\section{Data Collection and Analysis}

Data were obtained from analysis of results performed utilizing the Statistical Package for Social Sciences (version 25, SPSS, Inc., Chicago, IL). This study utilized descriptive statistics, consisting of means, frequencies, and percentages as well as chi square analyses to report results that described and compared the current status of policies and procedures between employment models (directly employed, outreach). 


\section{RESULTS}

From a sample size of $4000(n=4000), 253$ surveys were completed for a response rate of $6.33 \%$. Of the 253 responses, 232 participants were selected for the final data analysis. The inclusion criteria for this study were: a) a certified athletic trainer, b) currently working in the secondary school setting, and c) living in the United States. Twenty-one participants were eliminated from the final analysis for not meeting the inclusion criteria: twenty participants reported not being currently employed at a secondary school and one participant was eliminated for not currently living in the United States.

The two employment models observed were as follows: $59.9 \%(n=139)$ identified as directly employed, where the athletic trainer was directly hired by the school they work for and $40.1 \%(n=93)$ identified as outreach employed or outreach model, where the athletic trainer was not directly hired by the school where they are working.

Participants in this study reported a variety of degree levels; $28.9 \%$ ( $n=67$ ) of participants earned a Bachelor's degree, $69.0 \%$ $(n=160)$ earned a Master's degree and $1.7 \%(n=4)$ earned a Doctoral degree; $0.4 \%(n=1)$ did not respond. The mean age of the participants was $37.9 \pm 11.8$ with a range of 22 to 70 years of age; $57.3 \%$ of participants were female $(n=133), 41.8 \%$ were male $(n=97)$ and $0.9 \%(n=2)$ did not respond. Additional demographic data are presented in Table 1.

Table 1. Demographic Information of Participants

\begin{tabular}{llllll}
\hline & N & Minimum & Maximum & M & SD \\
\hline Years of Certification & 230 & 1 & 46 & 14.2 & 10.8 \\
Years in Secondary School Setting & 231 & $<1$ & 42 & 11.8 & 9.9 \\
Years in Current Position & 230 & $<1$ & 35 & 8.5 & 8.1 \\
Average Hours Per Week & 230 & 7 & 80 & 42.0 & 14.5 \\
Age of Participant & 224 & 22 & 70 & 37.9 & 11.8 \\
\hline
\end{tabular}

Distribution of participants across National Athletic Trainers' Association (NATA) districts are presented in Table 2. Six states and the District of Columbia had no participants across four districts, which included Rhode Island, Vermont, Kansas, North Dakota, Alaska, and Idaho. Five participants did not indicate their state or district of employment.

Table 2. Frequency and Employment Model of Participants by NATA District ( $\mathrm{N}=232)$

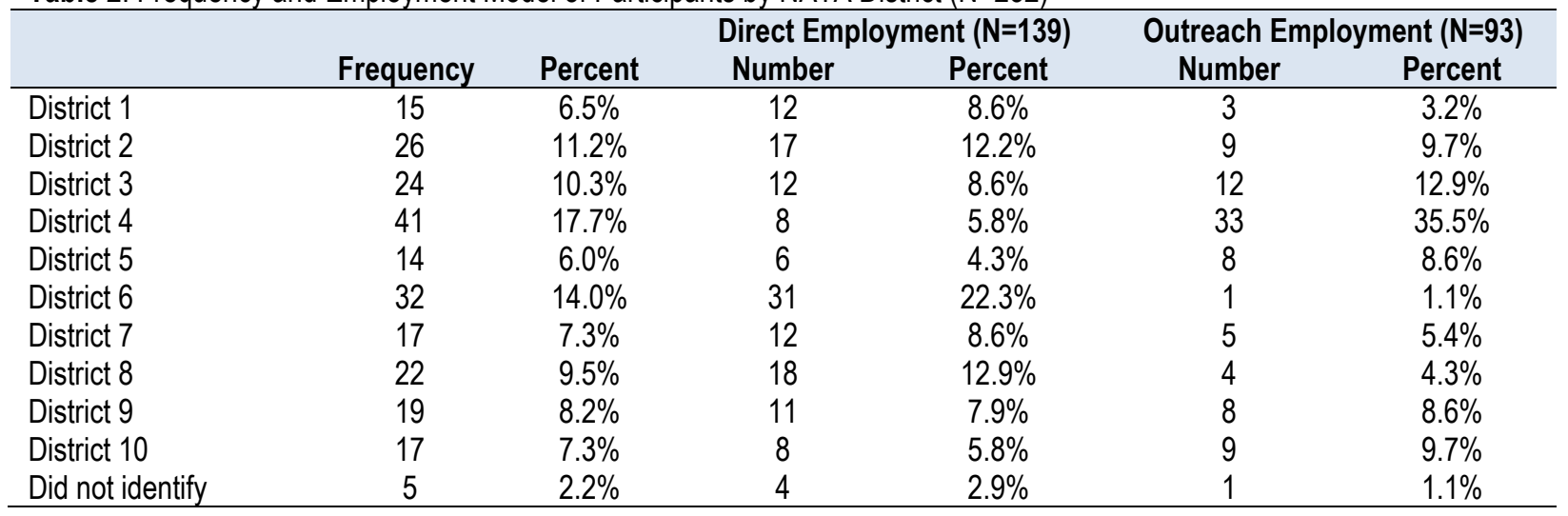

Using the same data analyzed from the Policies and Procedures Status Questionnaire, two chi square, non-parametric analyses were used to compare the frequency of operational and written practice status between employment models. A phi coefficient was also utilized to determine the degree of association between policy and procedure status and employment model. The closer the value of the phi coefficient is to $+/-1$ the stronger the degree of association is between the two variables. Interpretation of the phi coefficient is listed in Table 3. 
Table 3. Phi Coefficient Interpretation

\begin{tabular}{c|c}
\hline Phi Coefficient & Association \\
\hline-1.0 to -0.7 & Strong negative association \\
-0.7 to -0.3 & Weak negative association \\
-0.3 to +0.3 & Little or no association \\
+0.3 to +0.7 & Weak positive association \\
+0.7 to +1.0 & Strong positive association \\
\hline
\end{tabular}

The first chi square analysis compared employment model and operational practice status. This data can be seen in Table 4 .

Table 4. Frequency of Policies and Procedures Reported to be In Operation

\begin{tabular}{|c|c|c|c|c|c|}
\hline Operational Policy or Procedure & $\begin{array}{c}\text { Outreach } \\
\text { Employment }\end{array}$ & $\begin{array}{c}\text { Direct } \\
\text { Employment }\end{array}$ & Total & $x^{2}$ & $\phi$ \\
\hline Annual Review of P\&P & $59.8 \%$ & $43.2 \%$ & $49.8 \%$ & $0.013^{*}$ & 0.163 \\
\hline Consulting the Physician on P\&P & $68.8 \%$ & $61.2 \%$ & $64.2 \%$ & 0.233 & 0.078 \\
\hline Consulting other ATs on P\&P & $75.6 \%$ & $65.7 \%$ & $69.6 \%$ & 0.114 & 0.105 \\
\hline Consulting EMS on P\&P & $48.4 \%$ & $43.2 \%$ & $45.3 \%$ & 0.434 & 0.051 \\
\hline Consulting the Athletic Director on P\&P & $90.3 \%$ & $80.6 \%$ & $84.5 \%$ & $0.044^{*}$ & 0.132 \\
\hline Consulting the School Nurse on P\&P & $57.0 \%$ & $51.8 \%$ & $53.9 \%$ & 0.437 & 0.051 \\
\hline Consulting Legal Counsel on P\&P & $31.2 \%$ & $31.2 \%$ & $31.2 \%$ & 0.997 & 0.000 \\
\hline Consulting the School Counselor on P\&P & $28.0 \%$ & $21.9 \%$ & $24.3 \%$ & 0.239 & 0.069 \\
\hline HIPAA/FERPA & $52.7 \%$ & $43.9 \%$ & $47.4 \%$ & 0.188 & 0.086 \\
\hline OSHA/BBP & $66.3 \%$ & $53.2 \%$ & $58.4 \%$ & $0.049^{*}$ & 0.130 \\
\hline CPR/AED & $93.5 \%$ & $83.5 \%$ & $87.5 \%$ & $0.023^{*}$ & 0.150 \\
\hline Communicable Disease & $74.2 \%$ & $49.6 \%$ & $59.5 \%$ & $0.000^{*}$ & 0.245 \\
\hline Assumption of Risk & $76.3 \%$ & $61.2 \%$ & $67.2 \%$ & $0.016^{*}$ & 0.159 \\
\hline Confidentiality/Security & $87.9 \%$ & $73.4 \%$ & $79.1 \%$ & $0.008^{*}$ & 0.175 \\
\hline Release of Information & $87.1 \%$ & $69.8 \%$ & $76.7 \%$ & $0.002^{*}$ & 0.201 \\
\hline PPE Completion/Documentation & $95.7 \%$ & $89.9 \%$ & $92.2 \%$ & 0.104 & 0.107 \\
\hline Consent to Treat & $92.5 \%$ & $81.3 \%$ & $85.8 \%$ & $0.017^{*}$ & 0.157 \\
\hline Concussion Baseline Testing & $90.3 \%$ & $78.4 \%$ & $83.2 \%$ & $0.017^{*}$ & 0.156 \\
\hline EAP in Venues & $94.6 \%$ & $89.2 \%$ & $91.4 \%$ & 0.150 & 0.095 \\
\hline Concussion Management & $98.9 \%$ & $93.5 \%$ & $95.7 \%$ & $0.049^{*}$ & 0.130 \\
\hline Spinal Injury & $95.7 \%$ & $90.6 \%$ & $92.7 \%$ & 0.148 & 0.095 \\
\hline Equipment Removal & $94.6 \%$ & $87.8 \%$ & $90.5 \%$ & 0.081 & 0.115 \\
\hline Asthma & $97.8 \%$ & $85.5 \%$ & $90.4 \%$ & $0.002^{*}$ & 0.205 \\
\hline Heat IIIness & $96.7 \%$ & $88.4 \%$ & $91.7 \%$ & $0.025^{\star}$ & 0.148 \\
\hline Weather Emergency & $98.9 \%$ & $87.1 \%$ & $91.8 \%$ & $0.001^{*}$ & 0.211 \\
\hline Exertional Sickling & $81.5 \%$ & $63.0 \%$ & $70.4 \%$ & $0.003^{*}$ & 0.198 \\
\hline Weapons Management & $65.2 \%$ & $54.0 \%$ & $58.4 \%$ & 0.089 & 0.112 \\
\hline Sudden Cardiac Arrest & $96.8 \%$ & $89.1 \%$ & $92.2 \%$ & $0.034^{*}$ & 0.140 \\
\hline Wound Care & $92.5 \%$ & $87.8 \%$ & $89.7 \%$ & 0.249 & 0.076 \\
\hline Chemical/Substance Abuse & $67.7 \%$ & $61.6 \%$ & $64.1 \%$ & 0.340 & 0.063 \\
\hline Physical/Sexual/Emotional Abuse & $81.7 \%$ & $69.3 \%$ & $74.3 \%$ & $0.035^{\star}$ & 0.139 \\
\hline Diabetes & $86.0 \%$ & $74.6 \%$ & $79.2 \%$ & $0.036^{*}$ & 0.138 \\
\hline Eating Disorder & $73.1 \%$ & $57.6 \%$ & $63.8 \%$ & $0.016^{*}$ & 0.159 \\
\hline Pregnancy & $39.8 \%$ & $33.1 \%$ & $35.8 \%$ & 0.297 & 0.068 \\
\hline Weight Management & $64.5 \%$ & $56.1 \%$ & $59.5 \%$ & 0.201 & 0.084 \\
\hline Return to Play & $98.9 \%$ & $91.4 \%$ & $94.4 \%$ & $0.014^{*}$ & 0.161 \\
\hline Prescription Drug Storage/Use & $63.7 \%$ & $50.4 \%$ & $55.7 \%$ & $0.046^{*}$ & 0.132 \\
\hline OTC Drug Storage/Use & $75.8 \%$ & $57.6 \%$ & $64.8 \%$ & $0.005^{*}$ & 0.187 \\
\hline Referral to a Physician & $91.4 \%$ & $57.7 \%$ & $87.0 \%$ & 0.104 & 0.107 \\
\hline Referral to a Physical Therapist & $80.6 \%$ & $61.9 \%$ & $69.4 \%$ & $0.002^{*}$ & 0.200 \\
\hline Referral to a Nutritionist & $46.2 \%$ & $33.8 \%$ & $38.8 \%$ & 0.057 & 0.125 \\
\hline
\end{tabular}




\begin{tabular}{llllll} 
Referral for Mental Health & $67.7 \%$ & $56.5 \%$ & $61.0 \%$ & 0.086 & 0.113 \\
Modality Annual Inspection & $66.3 \%$ & $60.4 \%$ & $62.8 \%$ & 0.366 & 0.059 \\
Facility Cleaning & $79.6 \%$ & $73.4 \%$ & $75.9 \%$ & 0.280 & 0.071 \\
GFI Annual Inspection & $62.6 \%$ & $46.7 \%$ & $53.1 \%$ & $0.018^{*}$ & 0.156 \\
Athletic Trainer Job Outline & $93.5 \%$ & $82.0 \%$ & $86.6 \%$ & $0.011^{*}$ & 0.166 \\
Physician Job Outline & $78.5 \%$ & $65.2 \%$ & $70.6 \%$ & $0.030^{*}$ & 0.143 \\
Athletic Training Student Job Outline & $63.7 \%$ & $58.6 \%$ & $61.4 \%$ & 0.555 & 0.039 \\
Graduate Assistant Job Outline & $31.5 \%$ & $29.9 \%$ & $30.6 \%$ & 0.797 & 0.017 \\
\hline
\end{tabular}

Note: $\mathrm{N}=232, \mathrm{P} \& \mathrm{P}=$ policies and procedures manual, $\mathrm{X} 2=$ Chi Square, $\phi=$ Phi Coefficient, ${ }^{*} \mathrm{p}<.05$.

When comparing the two employment models the chi square analysis revealed $x 2(1,232)=0.000, p<.05$ with a phi coefficient value of $\phi=.245$ indicating a significant difference between the two employment models with little to no association between the two variables. The phi coefficient indicates that $6 \%$ of the variance in reporting the status of the operational policy is due to employment model. Out of 49 variables tested, 26 variables were found to be clinically significant $(p<.05)$. Overall, $75.5 \%$ of outreach employed athletic trainers reported having these risk management practices in operation whereas $64.8 \%$ of directly employed athletic trainers reported having the same risk management practices in operation.

The second chi square analysis compared employment model and written practice status. This data can be seen in Table 5.

Table 5. Frequency of Policies and Procedures Reported to be In Written Form

\begin{tabular}{|c|c|c|c|c|c|}
\hline Written Policy or Procedure & $\begin{array}{c}\text { Outreach } \\
\text { Employment }\end{array}$ & $\begin{array}{c}\text { Direct } \\
\text { Employment }\end{array}$ & Total & $x^{2}$ & $\phi$ \\
\hline Annual Review of P\&P & $69.6 \%$ & $51.8 \%$ & $58.9 \%$ & $0.007^{*}$ & 0.177 \\
\hline Consulting the Physician on P\&P & $50.5 \%$ & $39.6 \%$ & $44.0 \%$ & 0.099 & 0.108 \\
\hline Consulting other ATs on P\&P & $40.0 \%$ & $28.5 \%$ & $33.0 \%$ & 0.071 & 0.120 \\
\hline Consulting EMS on P\&P & $40.9 \%$ & $17.3 \%$ & $26.7 \%$ & $0.000^{*}$ & 0.261 \\
\hline Consulting the Athletic Director on P\&P & $60.2 \%$ & $38.1 \%$ & $47.0 \%$ & $0.001^{*}$ & 0.217 \\
\hline Consulting the School Nurse on P\&P & $29.0 \%$ & $20.1 \%$ & $23.7 \%$ & 0.119 & 0.102 \\
\hline Consulting Legal Counsel on P\&P & $25.8 \%$ & $19.6 \%$ & $22.1 \%$ & 0.262 & 0.074 \\
\hline Consulting the School Counselor on P\&P & $21.5 \%$ & $8.8 \%$ & $13.9 \%$ & $0.006^{*}$ & 0.181 \\
\hline HIPAA/FERPA & $38.7 \%$ & $30.2 \%$ & $33.6 \%$ & 0.18 & 0.088 \\
\hline OSHA/BBP & $56.5 \%$ & $39.6 \%$ & $46.3 \%$ & $0.011^{*}$ & 0.166 \\
\hline CPR/AED & $80.6 \%$ & $61.2 \%$ & $69.0 \%$ & $0.002^{*}$ & 0.207 \\
\hline Communicable Disease & $55.9 \%$ & $28.8 \%$ & $39.7 \%$ & $0.000^{*}$ & 0.272 \\
\hline Assumption of Risk & $72.0 \%$ & $48.9 \%$ & $58.2 \%$ & $0.000^{*}$ & 0.230 \\
\hline Confidentiality/Security & $73.6 \%$ & $47.5 \%$ & $57.8 \%$ & $0.000^{*}$ & 0.259 \\
\hline Release of Information & $76.3 \%$ & $43.9 \%$ & $56.9 \%$ & $0.000^{*}$ & 0.321 \\
\hline PPE Completion/Documentation & $92.5 \%$ & $79.0 \%$ & $84.4 \%$ & $0.006^{*}$ & 0.182 \\
\hline Consent to Treat & $86.0 \%$ & $62.6 \%$ & $72.0 \%$ & $0.000^{*}$ & 0.256 \\
\hline Concussion Baseline Testing & $87.1 \%$ & $68.3 \%$ & $75.9 \%$ & $0.001^{*}$ & 0.215 \\
\hline EAP in Venues & $94.6 \%$ & $81.3 \%$ & $86.6 \%$ & $0.003^{*}$ & 0.192 \\
\hline Concussion Management & $98.9 \%$ & $84.9 \%$ & $90.5 \%$ & $0.000^{*}$ & 0.234 \\
\hline Spinal Injury & $65.6 \%$ & $51.1 \%$ & $56.9 \%$ & $0.029^{*}$ & 0.144 \\
\hline Equipment Removal & $60.2 \%$ & $41.7 \%$ & $49.1 \%$ & $0.006^{*}$ & 0.181 \\
\hline Asthma & $69.6 \%$ & $44.9 \%$ & $54.8 \%$ & $0.000^{*}$ & 0.243 \\
\hline Heat IIIness & $84.8 \%$ & $65.9 \%$ & $73.5 \%$ & $0.002^{*}$ & 0.209 \\
\hline Weather Emergency & $83.7 \%$ & $72.7 \%$ & $77.1 \%$ & 0.051 & 0.128 \\
\hline Exertional Sickling & $57.6 \%$ & $26.8 \%$ & $39.1 \%$ & $0.000^{*}$ & 0.309 \\
\hline Weapons Management & $69.9 \%$ & $40.3 \%$ & $51.9 \%$ & $0.000^{*}$ & 0.287 \\
\hline Sudden Cardiac Arrest & $82.8 \%$ & $69.9 \%$ & $74.9 \%$ & $0.023^{*}$ & 0.150 \\
\hline Wound Care & $72.0 \%$ & $48.9 \%$ & $58.2 \%$ & $0.000^{*}$ & 0.230 \\
\hline Chemical/Substance Abuse & $62.4 \%$ & $30.4 \%$ & $43.3 \%$ & $0.000^{*}$ & 0.316 \\
\hline Physical/Sexual/Emotional Abuse & $68.8 \%$ & $50.4 \%$ & $57.8 \%$ & $0.005^{*}$ & 0.183 \\
\hline Diabetes & $63.4 \%$ & $41.3 \%$ & $50.2 \%$ & $0.001^{*}$ & 0.217 \\
\hline Eating Disorder & $51.6 \%$ & $23.7 \%$ & $34.9 \%$ & $0.000^{*}$ & 0.287 \\
\hline Pregnancy & $23.7 \%$ & $15.1 \%$ & $18.5 \%$ & 0.101 & 0.108 \\
\hline
\end{tabular}




\begin{tabular}{|c|c|c|c|c|c|}
\hline Weight Management & $40.9 \%$ & $22.3 \%$ & $29.7 \%$ & $0.002^{*}$ & 0.199 \\
\hline Return to Play & $89.2 \%$ & $66.2 \%$ & $75.4 \%$ & $0.000^{*}$ & 0.263 \\
\hline Prescription Drug Storage/Use & $60.4 \%$ & $38.1 \%$ & $47.0 \%$ & $0.001^{*}$ & 0.219 \\
\hline OTC Drug Storage/Use & $70.3 \%$ & $41.7 \%$ & $53.0 \%$ & $0.000^{*}$ & 0.280 \\
\hline Referral to a Physician & $84.9 \%$ & $37.7 \%$ & $56.7 \%$ & $0.000^{*}$ & 0.468 \\
\hline Referral to a Physical Therapist & $54.8 \%$ & $27.3 \%$ & $38.4 \%$ & $0.000^{*}$ & 0.277 \\
\hline Referral to a Nutritionist & $29.0 \%$ & $9.4 \%$ & $17.2 \%$ & $0.000^{*}$ & 0.255 \\
\hline Referral for Mental Health & $51.6 \%$ & $18.8 \%$ & $32.0 \%$ & $0.000^{*}$ & 0.344 \\
\hline Modality Annual Inspection & $48.9 \%$ & $30.9 \%$ & $38.1 \%$ & $0.006^{*}$ & 0.059 \\
\hline Facility Cleaning & $57.0 \%$ & $30.9 \%$ & $41.4 \%$ & $0.000^{*}$ & 0.259 \\
\hline GFI Annual Inspection & $41.8 \%$ & $26.3 \%$ & $32.5 \%$ & $0.014^{*}$ & 0.162 \\
\hline Athletic Trainer Job Outline & $91.4 \%$ & $69.8 \%$ & $78.4 \%$ & $0.000^{*}$ & 0.258 \\
\hline Physician Job Outline & $66.7 \%$ & $39.1 \%$ & $50.2 \%$ & $0.000^{*}$ & 0.270 \\
\hline Athletic Training Student Job Outline & $56.0 \%$ & $44.5 \%$ & $49.1 \%$ & 0.088 & 0.113 \\
\hline Graduate Assistant Job Outline & $29.3 \%$ & $21.2 \%$ & $24.5 \%$ & 0.158 & 0.093 \\
\hline
\end{tabular}

Note: $\mathrm{N}=232, \mathrm{P} \& \mathrm{P}=$ policies and procedures manual, $\mathrm{X} 2=$ Chi Square, $\phi=$ Phi Coefficient, ${ }^{*} p<.05$

When comparing the two employment models the chi square analysis revealed that $\chi 2(1,232)=0.000, p<.05$ with a phi coefficient of 468 indicating a significant difference between the two employment models and a weak positive association between the two variables. The phi coefficient indicates that $21.9 \%$ of the variance in reporting the status of the written policy is due to employment model. Out of 49 variables, 40 variables were found to be clinically significant $(p<.05)$. Overall, $62 \%$ of outreach employed athletic trainers reported having these risk management practices in written form whereas $41.8 \%$ of directly employed athletic trainers reported having the same risk management practices in written form.

\section{DISCUSSION}

The purpose of this study was to identify the policy and procedure practices of secondary school athletic trainers based upon employment models. To be effective, P\&Ps should be in written form and operationalized into daily practice. An earlier study by Dunbar-Gaynor et al15 identified nearly three-quarters $(72.6 \%)$ of secondary school athletic trainers had existing P\&P manuals and $45.7 \%$ had policies in both operational and written form. This was similar to Zimmerman's research on collegiate athletic training department P\&Ps. ${ }^{17}$ The data suggests athletic trainers, whether in the secondary school or university setting, are not consistently developing and implementing P\&Ps in both a written form and operationalizing them into daily practice. This study wanted to compare the policy and procedure practices of secondary school athletic trainers to employment model - direct employment and outreach employment.

In this study $59.9 \%$ of participants in the US were directly employed by the secondary school and $40.1 \%$ were employed by the outreach model. The employment characteristics of secondary school ATs vary across recent studies. A 2010 study by Wham et al 14 identified $36 \%$ of ATs were employed by the secondary school and $42 \%$ of ATs were outreach in South Carolina, whereas a 2018 study ${ }^{9}$ in Arizona identified $78 \%$ of ATs were employed by the secondary school and $22 \%$ employed by an outside clinic or hospital. A study ${ }^{16}$ from 2013 examined the practice characteristics of secondary school ATs across the US and identified $47.1 \%$ of ATs were directly employed by schools full-time and $14.0 \%$ of ATs were outreach. Direct employed ATs are employed by the secondary school or school district. The immediate AT supervisor may be the Athletic Director, Principle, or Superintendent, and is primarily a non-healthcare provider. Outreach employed ATs are generally employed through a larger company or organization that is responsible for its own policy and procedure manual. Many outreach employers, such as hospitals and rehabilitation facilities, are accredited through organizations with established standards governing the safety and quality of patient care, such as the Joint Commission on Accreditation of Healthcare Organizations (JCAHO) or the Commission on Accreditation of Rehabilitation Facilities (CARF).

Outreach employed ATs reported having $75.5 \%$ of risk management practices in operation and $62 \%$ in written form. Directly employed ATs reporting having $64.8 \%$ of risk management practices in operation and $41.8 \%$ in written form. Overall, outreach employed ATs reported having risk management practices in operation and written form more than ATs directly employed by the secondary school. No accrediting body exists with established standards governing athletic training facilities, as there are for other health care professions. While all secondary school ATs, regardless of employment model, have access to and may use tools such as the BOC guidelines on facilities, policies, and procedures and the NATA sample outlines of policies and procedures ATs employed in the outreach model may also have access to additional resources (e.g., JCAHO, CARF).3,4,15,18 
Regardless of employment status, secondary school ATs are not consistently developing and implementing P\&Ps in both written and operational form. A study by Williams et $\mathrm{a}^{13}$ found the directly employed ATs, regardless of full/part-time status, were more familiar with academic accommodation services provided and generally provided more concussed students with those accommodations compared to ATs employed in the outreach model, suggesting that directly employed ATs provide a higher standard of concussion management over outreach ATs. Other studies have concluded that access to an AT rather than the employment model was likely to result in policies and procedures in the secondary school setting.,9,14

The secondary school AT may have limited time, guidance, training, and resources around risk management, which may be influenced by the employment model. For example, the outreach AT may only be scheduled part-time at the secondary school or a directly employed AT may also be responsible for teaching courses; this could limit time available to develop P\&Ps. The number of ATs in the secondary school may also influence the development, implementation, and maintenance of P\&Ps. A single AT in a secondary school, regardless of employment model, may also have limited availability to develop P\&Ps. In addition to time, access to these resources could be a factor. There are professional position statements and multi-disciplinary consensus statements that outline best practices ${ }^{1,19}$, along with tools from the BOC ${ }^{3,18}$ and NATA. ${ }^{4}$ When reviewing the study by Dunbar-Gaynor et a $\left.\right|^{15}$ on the policy and procedure status of secondary school athletic trainers, the P\&Ps were more likely than the average $(45.7 \%)$ to be in written and operational form if there was a professional position statement, such as concussion management $(88.7 \%)$, emergency action plans $(81.9 \%)$, heat illness $(70 \%)$, weather emergencies $(74.5 \%)$, asthma $(53.5 \%)$ and diabetes (48.9\%). However, a clearinghouse does not exist that provides best practices in risk management or P\&P development for the secondary school athletic training room, regardless of employment setting.

The level of policy making could also have an influence, as health and safety policies are implemented or mandated at the state level and not by the National Federation of State High School Associations (NFHS); the NFHS does not have governing authority for secondary school athletics. Adams et a ${ }^{12}$ found a large variability in the implementation of evidence-based best practice policies for preventing sudden death and catastrophic injuries in secondary school athletics. A 2018 study ${ }^{11}$ of health and safety policies across 50 states and the District of Columbia found inconsistency on policies that meet best-practice recommendations for the leading causes of sudden death in state high school athletic associations (SHSAA).

The Dunbar-Gaynor et a ${ }^{15}$ study suggestions secondary school ATs recognize the importance of risk management and having P\&Ps. However, ATs may be limited in developing, implementing, and maintaining P\&Ps by time, access to resources, inconsistency in state policies, and supervisor role. The socioecological framework20,21 as an approach for interventions to reduce sports-related deaths in secondary school has recently been introduced in the profession. ${ }^{22,23}$ It is possible that introducing a framework for developing and implementing P\&Ps in the secondary schools could influence change and should be further explored. The findings of this study indicate that while outreach employed ATs have a majority of P\&Ps in both written and operational form, there continues to be inconsistency regardless of employment model.

\section{LIMITATIONS}

There are limitations acknowledged in this study. The researchers in this study assumed that the participants were both knowledgeable and honest about the status of their employment and P\&P manuals. This study did not evaluate each individual P\&P for compliance with best practices. This study did not examine the position, title, or role of the participants' supervisor on the employment model or P\&P development and implementation. This study did not examine the utilization of resources from JCAHO or CARF.

\section{CONCLUSION}

There is limited research on the relationship of AT employment (direct vs outreach) and secondary school policy and procedure manual status. From this study, it has been reported that outreach athletic training employment model have a majority of policies and procedures in both written and operational form over participants who identified as directly employed athletic trainers. Increasing the amount of policy and procedure manuals in secondary schools could lead to increased conversation about the status of policies and procedures in relation to emergency preparedness and preventing sudden death in secondary schools athletics.

This study establishes a baseline of current risk management practices for ATs working in secondary school in either the direct or outreach employment model. Future research exploring the role of secondary school AT's supervisor on P\&P development and implementation, along with examining the utilization of types of resources utilized, could add to the narrative of secondary school policy and procedure manuals and risk management practices.

[Note: For a copy of the survey instrument used in this study, contact the PI at mdunbar-gaynor@adrian.edu] 


\section{REFERENCES}

1. Almquist J, Valovich McLeod TC, Cavanna A, et al. Summary statement: Appropriate medical care for the secondary school-aged athlete. J Athl Train. 2008; 43(4), 416-427. doi: 10.4085/1062-6050-43.4.416 [PMID: 18668175]

2. Lyznicki JM, Riggs JA, \& Champion HC. Certified athletic trainers in secondary schools: Report of the council on scientific affairs, American Medical Association. J Athl Train. 1999;34(3), 272-276. [PMID: 16558576]

3. Board of Certification, Inc. Guiding principles for AT policy and procedure development. Retrieved from http://www.bocatc.org/system/comfy/cms/files/files/000/000/529/original/Guiding_Principles_for_AT_Policies_and_Procedur es .pdf. Published 2016. Accessed March 15, 2019.

4. NATA. Standard operating policies and procedures. Retrieved from: https://www.nata.org/blog/jordanb/ secondary-schoolresources. Published 2014. Accessed March 15, 2019.

5. NATA. Job Settings. Retrieved from: https://www.nata.org/about/athletic-training/job-settings. Published 2019. Accessed on January $3,2020$.

6. Pryor RR, Casa DJ, Vandermark LW, Stearns RL, Attanasio SM, Fontaine G., \& Wafer AM. Athletic training services in public secondary schools: A benchmark study. J Athl Train. 2015; 50(2), 156-162. doi.org/10.4085/1062-6050-50.2.03. [PMID: 25689559]

7. NATA. Position proposal guide for certified athletic trainers in secondary school athletics programs. Retrieved from: https://www.nata.org/sites/default/files/secondary-school-position-proposal-guide.pdf. Published 2013. Accessed on January $3,2020$.

8. Paddack M, DeWolf R, Covassin T, \& Kontos A. Policies, procedures, and practices regarding sport-related concussion in community college athletes. J Athl Train. 2016; 51(1), 82-88. doi: 10.4085/1062-6050-51.2.01 [PMID: 26765512]

9. Valovich McLeod TC \& Cardenas JF. Emergency preparedness of secondary school athletic programs in Arizona. J Athl Train. 2018. doi: 10.4085/1062-6050-35-18. [Epub ahead of print] [PMID: 30517023]

10. Scarneo SE, DiStefano LJ, Stearns RL, Register-Mihalik JK, Denegar CR, and Casa DJ. Emergency action planning in secondary school athletics: A comprehensive evaluation of current adoption of best practice standards. J Athl Train. 2019; 54(1), 99-105. doi.org/10.4085/1062-6050-82-18 [PMID: 30676786]

11. Adams WM, Scarneo SE, and Casa DJ. Assessment of evidence-based health and safety polices on sudden death and concussion management in secondary school athletics: A benchmark study. J Athl Train. 2018; 53(8), 756-767. doi: 10.4085/1062-6050-220-17. [PMID: 30212234]

12. Adams WM, Scarneo SE, and Casa DJ. State-level implementation of health and safety policies to prevent sudden death and catastrophic injuries within secondary school athletics. Ortho J of Sports Med. 2017; 5(9). doi: 10.1177/2325967117727262. [PMID: 28951881]

13. Williams RM, Welch CE, Parson JT, \& Valovich McLeod TC. Athletic trainers' familiarity with and perceptions of academic accommodations in secondary school athletes after sport-related concussion. J Athl Train. 2015; 50(3), 262-260. Doi: 10.4085/1062-6050-49.3.81. [PMID: 25562456]

14. Wham GS, Saunders R, \& Mensch J. Key factors for providing appropriate medical care in secondary school athletics: Athletic training services and budget. J Athl Train. 2010; 45(1), 75-86. doi.org/10.4085/1062-6050-45.1.75 [PMID: 20064052]

15. Dunbar-Gaynor M, Zimmerman EP, and Liberi V. An examination of policy and procedure practices of secondary school athletic trainers. Internet Journal of Allied Health Sciences and Practice. 2020; 18(2). 
16. Valovich McLeod TC, Huxel Bliven KC, Lam KC, Bay RC, Snyder Valier AR, \& Parsons JT. The national sports safety in secondary schools benchmark (N4SB) study: Defining athletic training practice characteristics. J Athl Train. 2013; 48(4), 483-492. doi: 10.4085/1062-6050-48.4.04. [Epub 2013] [PMID: 23768120]

17. Zimmerman EP. Risk management practices of collegiate athletic trainers: An examination of policies and procedures. Dissertation Abstracts International Section A: Humanities and Social Sciences. 2018. 68(10-A): 4165. https://login. proxy195.nclive.org/login?url=https://search.ebscohost.com/login. aspx?direct=true\&db=psyh\&AN=2008-99070015\&site=ehost-live\&scope=site. Accessed March 16, 2019.

18. Board of Certification, Inc. BOC facility principles. Retrieved from http://www.bocatc.org/system/document versions/versions/42/original/boc-facility-principles20170615. pdf?1497543426. Published 2013. Accessed March 15, 2019.

19. Courson $R$, Goldenberg $M$, Adams KG, et al. Inter-association consensus statement on best practices for sports medicine management for secondary schools and colleges. J Athl Train. 2014; 49(1), 128-137. doi: 10.4085/1062-6050-49.1.06 [PMID: 24499040]

20. Bronfenbrenner U. Toward an experimental ecology of human development. Am Psychol. 1977;32(7):513-531.

21. McLeroy KR, Bibeau D, Steckler A, Glanz A. An ecological perspective on health promotion programs. Health Educ Q. 1988;15(4):351-377.

22. Scarneo SE, Kerr ZY, Kroshus E, Register-Mihalik JK, Hosokawa Y, Stearns RL, DiStefano LJ, and Casa DJ. The socioecological framework: A multifaceted approach to preventing sports-related deaths in high school sports. J Athl Train. 2019; 54(3), 356-360. doi: 10.4085/1062-6050-173-18. [PMID: 30870600]

23. Register-Mihalik JK, Baugh C, Kroshus E, Kerr ZY, and Valovich McLeod TC. A multifactorial approach to sport-related concussion prevention and education: Application of the socioecological framework. J Athl Train. 2017; 52(3), 195-205. doi: 10.4085/1062-6050-51.12.02. [PMID: 28387550] 